\title{
Temporal trends in cusk eel sound production at a proposed US wind farm site
}

\author{
T. Aran Mooney ${ }^{1, *}$, Maxwell B. Kaplan1 ${ }^{1}$ Annamaria Izzi ${ }^{1,2}$, Luca Lamoni ${ }^{1,3}$, \\ Laela Sayigh ${ }^{1}$
}

\begin{abstract}
${ }^{1}$ Biology Department, Woods Hole Oceanographic Institution, Woods Hole, MA 02543, USA
${ }^{2}$ Northeast Fisheries Science Center, NOAA, 166 Water Street, Woods Hole, MA 02543, USA

${ }^{3}$ School of Biology, University of St. Andrews, Sir Harold Mitchell Building, St. Andrews, Fife KY16 9TH, UK
\end{abstract}

\begin{abstract}
Many marine organisms produce sound during key life history events. Identifying and tracking these sounds can reveal spatial and temporal patterns of species occurrence and behaviors. We describe the temporal patterns of striped cusk eel Ophidion marginatum calls across approximately 1 yr in Nantucket Sound, MA, USA, the location of a proposed offshore wind energy installation. Stereotyped calls typical of courtship and spawning were detected from April to October with clear diel, monthly, and seasonal patterns. Acoustic energy increased in the evenings and peaked during crepuscular periods, with the dusk call levels typically higher in energy and more rapid in onset than those from near-dawn periods. Increased call energy and substantial overlap of calls during certain periods suggest that many cusk eels were often calling simultaneously. Call energy (measured in energy flux density) peaked in July and patterns followed seasonal changes in sunrise and sunset. Sound levels were high (over $150 \mathrm{~dB}$ re $1 \mu \mathrm{Pa}^{2} \mathrm{~s}$ ) during the summer, indicating that this cusk eel population is a substantial contributor to the local soundscape. The stereotyped cusk eel signals and clear temporal energy patterns potentially provide a bioacoustic signal that can be used to monitor changes to the local environment and its soundscape.
\end{abstract}

KEY WORDS: Noise $\cdot$ Masking $\cdot$ Spawning $\cdot$ Reproduction $\cdot$ Management $\cdot$ Conservation

\section{INTRODUCTION}

Acoustic signals produced by marine organisms can be effective indicators of species occurrence and biological processes. Fish and invertebrate signals have been associated with spawning events (Lobel 1992, Luczkovich et al. 1999, Hawkins \& Amorim 2000), courtship (Mann \& Lobel 1995), feeding (Versluis et al. 2000, Radford et al. 2008a), and competition (Johnston \& Vives 2003). Sound is frequently used as a means of communication in marine species (Myrberg 1986, Lobel \& Mann 1995); it travels relatively efficiently in seawater, and can be used when visual cues are not available (i.e. in the aphotic zone, at night, or in turbid water). Diel or seasonal periods

\footnotetext{
*Corresponding author: amooney@whoi.edu
}

of increased activity (Lammers et al. 2008, Radford et al. 2008b) or correlations with particular physical conditions (e.g. temperature and salinity) can be tracked by monitoring soundscapes over time (Mann $\&$ Grothues 2009). Many species of fish demonstrate seasonal and spatial patterns of sound production (Montie et al. 2015). Identifying the temporal or spatial variability of biological sounds can provide useful information when managing certain stocks or habitats (Hernandez et al. 2013).

Tracking soniferous behaviors may also help quantify potential impacts of increasing anthropogenic noise. Human-produced noise stems from a variety of sources such as sonar (military and fish-finders), commercial shipping, resource exploration, resource

() The authors 2016. Open Access under Creative Commons by Attribution Licence. Use, distribution and reproduction are unrestricted. Authors and original publication must be credited.

Publisher: Inter-Research · www.int-res.com 
extraction, and offshore development (e.g. pile driving). Offshore wind farm construction and operational noise have raised a variety of concerns in European waters and have been shown to impact some marine mammals (Carstensen et al. 2006, Teilmann \& Carstensen 2012). Fewer studies exist for fish, but there are indications that some species, such as cod, increase in abundance adjacent to wind farms, perhaps finding shelter amongst the pilings (Lindeboom et al. 2011). While offshore wind farms are not yet in operation in US waters, this is likely to change in the near future, with several sites in stages of active planning and development. Monitoring the soundscape provides a mechanism to track the patterns of soniferous marine fauna within offshore wind energy areas, and enables efforts to establish whether noise from construction or operation alters acoustic behaviors or habitat use.

Wind farm energy development areas in the northeastern USA overlap with the habitat of many soundproducing marine mammals and fish, including the cusk eel (family Ophidiidae), a demersal, often deepwater fish found in temperate waters worldwide (Nielsen et al. 1999, Beaudry-Losique et al. 2011). Overall, the acoustic behavior of Ophidion marginatum (striped cusk eel; found in the Western North Atlantic) and O. rochei (Roche's snake blenny; found in the Eastern North Atlantic and Mediterranean Sea) are relatively well studied compared to other members of the family (Parmentier et al. 2010, Kéver et al. 2012, 2015). Their sounds, generated by swim-bladderassociated muscles, are produced during courtship and spawning (Courtenay 1971). Both males and females produce sound, although males appear to be more acoustically active (Mann et al. 1997). The signals are highly stereotyped broadband pulses with 2 dominant frequency peaks between 400 and $3000 \mathrm{~Hz}$, and are produced in bouts of 1 to 27 pulses (Mann et al. 1997, Sprague \& Luczkovich 2001). These sounds have been described in the laboratory but there are few published data from the natural environment (Mann et al. 1997). Sound production rates appear to be dependent on some environmental parameters, such as water temperature (Sprague \& Luczkovich 2001, Mann \& Grothues 2009, Kéver et al. 2015). There is some indication of daily patterns in their call rates, but these patterns have not been characterized in detail (Sprague \& Luczkovich 2001, Mann \& Grothues 2009), and monthly or seasonal trends have only been suggested (Perkins 2001). However, their stereotyped signals are associated with reproductive behaviors and therefore offer a clear means to identify and track these behaviors in the wild.
Here, we describe the baseline bioacoustic temporal patterns of the striped cusk eel $O$. marginatum, the only cusk eel species known to be present in the waters studied (Collette \& Klein-MacPhee 2002). We evaluate seasonal, lunar, and daily patterns in sound production in the area of Horseshoe Shoal, Nantucket Sound, MA, which is the site of the first proposed US offshore wind farm. Results are compared to environmental measures and provide a detailed assessment of the temporal bioacoustic patterns of this soniferous species.

\section{MATERIALS AND METHODS}

\section{Study area and recording methods}

Acoustic data were collected from 7 June 2012 until 18 July 2013 on Horseshoe Shoal, located in Nantucket Sound, MA, USA $\left(41.475^{\circ} \mathrm{N}, 70.314^{\circ} \mathrm{W}\right)$ (Fig. 1A). This is a sandy, shallow area on the south shore of Cape Cod, located roughly between the cape and the islands of Nantucket and Martha's Vineyard. The water depth was $\sim 12 \mathrm{~m}$ and recorders were placed in the middle of the water column (Fig. 1B).

Acoustic recordings were collected using DSG recorders (Loggerhead Instruments) sampling at $80 \mathrm{kHz}$, using a $40 \mathrm{kHz}$ low pass filter and a $10 \%$ duty cycle of $1 \mathrm{~min}$ every $10 \mathrm{~min}$. The recorder consists of a cylindrical PVC housing with a High Tech hydrophone $\left(-186 \mathrm{~dB}\right.$ re $1 \mathrm{~V} \mu \mathrm{Pa}^{-1}$, frequency range 2 to $37 \mathrm{kHz}$ ) attached to a microcomputer circuit board and powered by $24 \mathrm{D}$-cell alkaline batteries. The DSG board incorporates an additional $20 \mathrm{~dB}$ of gain and was calibrated with a $0.1 \mathrm{~V}$ (peak) frequency sweep from 2 to $100 \mathrm{kHz}$. Acoustic files were saved onto a SDHC flash memory card. Before each deployment, the hydrophone was coated with a thin layer of acoustically transparent zinc oxide cream to minimize potential biofouling. Recorders were deployed on polypropylene line, with the hydrophone oriented towards the surface, and held in place with a Danforth anchor. The rope led to a subsurface float and a surface orange buoy. The former was used to minimize effects of wave action and subsequent pressure changes or movements at the recorder. Attached to the buoy was a high-flyer with radar reflector, with the intended purpose of deterring fishing vessels from running over the mooring (Fig. 1B). Overall this was a relatively quiet recording setup, with only occasional noise caused by the chain, which was easily distinguishable from the fish calls. Recorders were rotated out ca. every 3 mo to download data and 

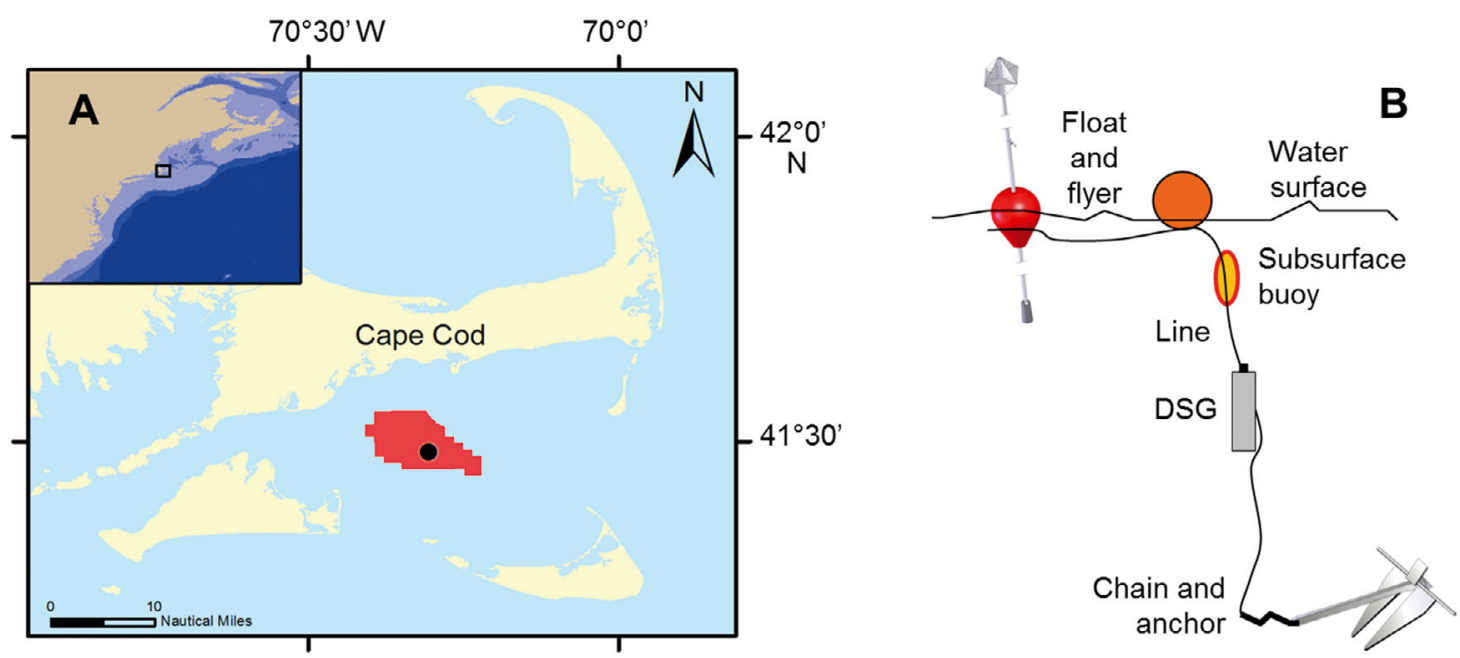

Fig. 1. (A) Location of acoustic recorder (•) and proposed wind farm (red block) in Nantucket Sound. (B) Recording setup; depth was approximately $12 \mathrm{~m}$

install new batteries. A small number of days were missed due to adverse weather conditions, which delayed some redeployments.

\section{Analyses}

Audio files were extracted from the SDHC cards, converted into WAV files, and then analyzed in several steps. Initially, sound files were viewed by a trained analyst using the acoustic software Raven Pro 1.5 (Charif et al. 2010). Recordings were imported into Raven one day at a time and the Window Preset function was used to maintain viewing consistency between days. The spectrogram settings used for viewing data included an FFT size of 4096 points with $75 \%$ overlap, a frequency range of 120 to $5000 \mathrm{~Hz}$, and a time axis of $30 \mathrm{~s}$.

In order to examine potential diel and/or seasonal patterns, the first minute from every hour was visually and aurally examined for Ophidion marginatum (hereafter referred to as cusk eel) calls and/or chorusing (Hernandez et al. 2013). Cusk eel calls were identified by comparing the signals' peak frequencies and inter-pulse-interval patterns to published values (Fig. 2; Mann et al. 1997, Sprague \& Luczkovich 2001), and their occurrence in relatively shallow water within the defined range of this species (Collette \& Klein-MacPhee 2002). A chorus was defined as constant 'chatter', which could be seen on the spectrogram as consistent energy between 600 and $2000 \mathrm{~Hz}$. Additional diagnostics for cusk eel chorusing included the presence of multiple overlapping calls, leading to a difficulty in distinguishing individual pulses. Cusk eel calls and chorusing were noted as either present or absent in each 1 min file assessed. Choruses inherently include call presence, but calls could occur without chorusing (i.e. a call is seen in Fig. 2). As only 1 min of every hour was assessed, the maximum number of times that calls or choruses could be tallied was 24 per day (i.e. every hour). While other sounds were noted, no fish, mammal, or anthropogenic sounds were similar to cusk eel calls, which allowed for relatively easy determination of signal presence. Days in which the acoustic recorder was deployed or retrieved were not assessed for diel patterns; however, these days were used in determining seasonal presence.

To acquire a series of good signal-to-noise pulse trains, 7 days were randomly chosen across each of June, July and August, and 3 hours from each of the 21 days were hand-browsed using Raven. All pulse trains within those hours that had a good signal-tonoise ratio (SNR) were selected using the highest values from Raven's energy and average power measurements. Several trains were not included because of overlap with boat or other noise; thus, the total number of good signal-to-noise pulse trains that were analyzed from the sampling scheme was 47 . Within each pulse train, measurements of pulse train duration, the number of pulses within a train, the pulse period $(\mathrm{ms})$, and pulse rate (pulses $\mathrm{s}^{-1}$ ) were made using custom Matlab (The MathWorks) scripts; peak frequency was calculated with Raven's peak frequency tool. Pulse period (described in some taxa as inter-click-interval) was defined as the time interval between the beginning of a pulse to the beginning of the next pulse and was equivalent to the inverse of the pulse repetition rate (Au 1993, Mann et al. 1997, Sprague \& Luczkovich 2001). Values were 

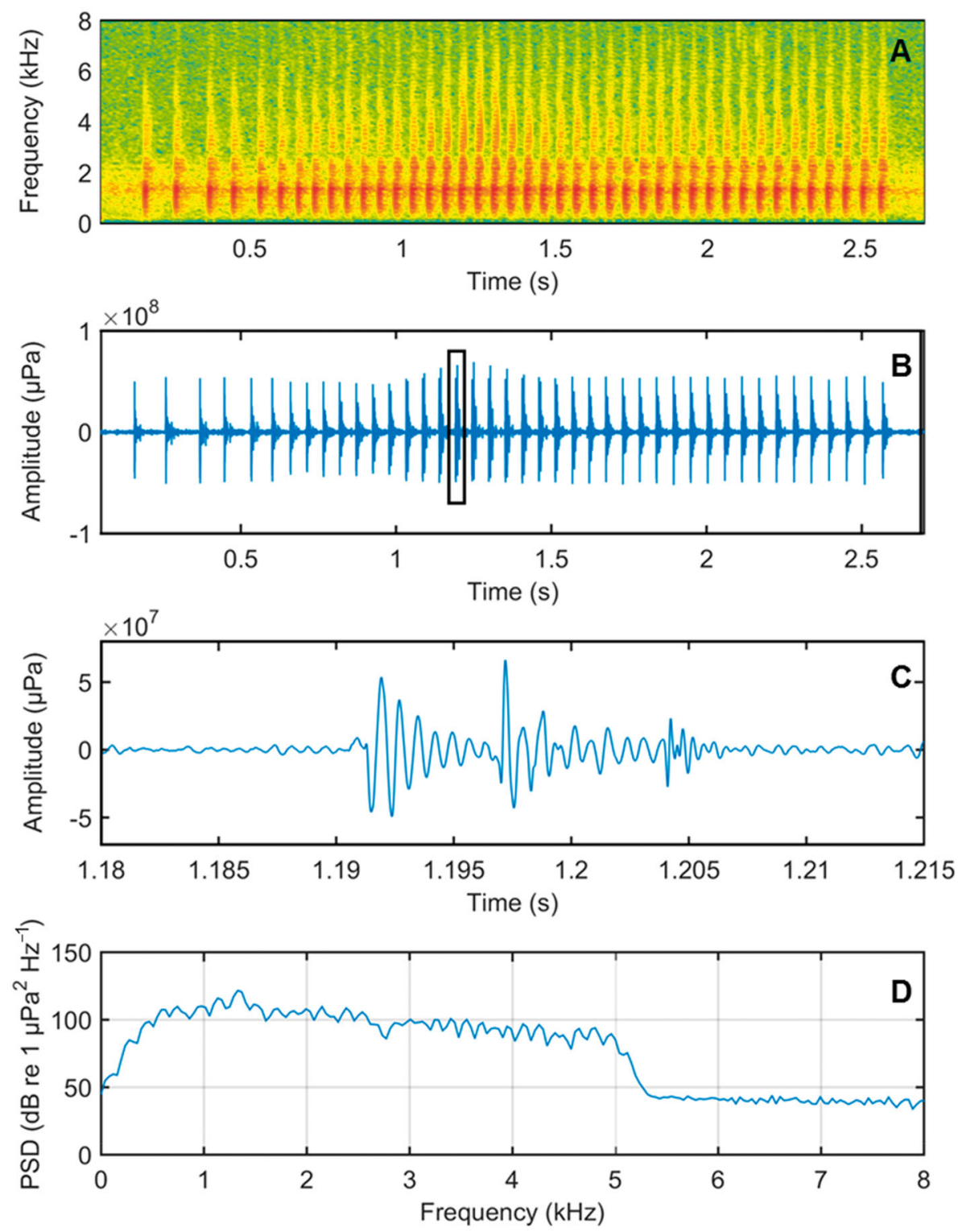

Fig. 2. (A) Spectrogram and (B) waveform of a striped cusk eel Ophidion marginatum pulse train. One pulse is highlighted in black in the waveform; its waveform is shown in (C) and a plot of its power spectral density (PSD) is shown in (D). Settings: fast Fourier transform (FFT) $=2048$, overlap $=80 \%$

compared to those of prior studies to confirm that the sounds produced were indeed from cusk eels (Fish \& Mowbray 1970, Mann et al. 1997, Perkins 2001, Sprague \& Luczkovich 2001, Rountree et al. 2002).

To test whether pulse trains were influenced by sea surface temperature, as was found by Sprague \& Luczkovich (2001), temperature data were obtained from NOAA Station 44020 for the hour that corresponded with each pulse train time. Using the statistical software package R (R Development Core Team 2010), linear regression models were generated to quantify the relationship. The temperature range in which calling was detected was also noted.
The intensity of cusk eel signals varied from faint individual calls with low signal-to-noise levels to clear intense choruses with many overlapping calls, making the usage of classic signal detectors challenging. Furthermore, because of substantial call overlap during choruses it was often not possible to discriminate individual calls for peak-to-peak sound pressure level (SPL, dB re $1 \mu \mathrm{Pa}$ ) measurements, nor was there an obvious duration over which we should integrate pulse trains for RMS SPL. Instead, the energy flux density (EFD, dB re $1 \mu \mathrm{Pa}^{2}$ s) within the cusk eel call band was taken as a relative measure of call/chorus intensity and all energy values are 
reported in EFD units unless otherwise stated. Each minute-long file was band pass filtered from 400 to $3000 \mathrm{~Hz}$ (cusk eel band) and the EFD was then calculated in Matlab. The use of EFD allowed us to report the overall variation in cusk eel sound levels and acoustic energy over time, thus better capturing the sound energy of faint calls, clear individual calls and choruses in a single sound level unit.

Visual assessments indicated clear differences in morning and evening choruses; thus, relevant sound files were grouped into either morning (01:00 to 05:00 h inclusive) or evening (19:00 to 23:00 $\mathrm{h}$ inclusive) time bands and were referred to as the morning and evening chorus or call periods. Maximum EFD values for the morning and evening time bands were extracted for each day. EFD of the cusk eel band was also analyzed across monthly and lunar time scales within the summer period (8 June to 14 September 2012), the time of year when choruses were present. All temporal differences in EFD were evaluated using Kruskal-Wallis tests, followed by Mann-Whitney post-hoc tests with Bonferroni corrections. Statistical analyses were done using $\mathrm{R}$.

\section{RESULTS}

\section{Individual call parameters and diel call patterns}

Recordings were made on $333 \mathrm{~d}$, with a total of 47952 data files of 1 min each. Cusk eel sounds were present on 164 of these days 112 of which also contained cusk eel choruses. Acoustic detections occurred from the end of Apri] until the end of October (Fig. 3) Calls were found at all times of day during the summer months (June to August; Fig. 3; see alsc Fig. S1 in the Supplement at www.int-res.com/articles/suppl/ b024p201_supp.pdf) with few times at which no calls were observed. Times lacking calls wer€ exclusively during the day (08:00 to $15: 00 \mathrm{~h})$.

The mean $( \pm \mathrm{SD})$ number of pulses per train, pulse period (ms) and pulse rate (pulses $\mathrm{s}^{-1}$ ) were $45( \pm 9), 58.5( \pm 12.1)$, and $18.2( \pm 3.3)$, respectively. Th $\epsilon$ mean $( \pm \mathrm{SD})$ peak frequency was $1.373( \pm 0.184) \mathrm{kHz}$ and the mear. duration of a pulse train was $2.49( \pm 0.4)$ s. Generally, these patterns reflected those of prior cusk eel studies (Fish \& Mowbray 1970, Mann et al. 1997, Perkins 2001, Sprague \& Luczkovich 2001, Rountree et al. 2002), with the greatest similarity to Rountree et al. (2002), who described a data set collected near Cape Cod. Similar to the results of Sprague \& Luczkovich (2001), the measured peak frequency increased with seawater temperature $\left(\mathrm{r}^{2}=0.73, \mathrm{p}<0.0001\right)$ and pulse period decreased with increasing temperature $\left(\mathrm{r}^{2}=\right.$ $0.89, \mathrm{p}<0.0001$; range $13.3-25.1^{\circ} \mathrm{C}$; Fig. 4). There was no relationship between water temperature and the number of pulses in a train $\left(\mathrm{r}^{2}=0.35, \mathrm{p}>0.05\right)$.

Two peaks in chorusing energy were noted on a diel basis (Fig. 5). The first peak occurred just after sunset and reached maximum energy relatively rapidly. A second peak occurred just before dawn and had a more gradual increase in energy. Peak energy levels differed significantly between morning and evening choruses (Kruskal-Wallis: $r=0.51$; MannWhitney $\left.U: \chi^{2}=50.02, \mathrm{p}<0.001\right)$. As a result, subsequent statistical analyses of peak energy levels were divided into morning and evening choruses. Night EFD levels were clearly elevated relative to day due to the high levels of cusk eel chorusing, which tended to increase at night (Fig. 5). During the day, individual, non-overlapping cusk eel calls were relatively frequent. Thus, EFD values during the day represent values of these individual calls as well as that of lower level 'chatter' (illustrated by the bracketed sounds before 21:10 h and after ca. 05:00 h in Fig. 5A).

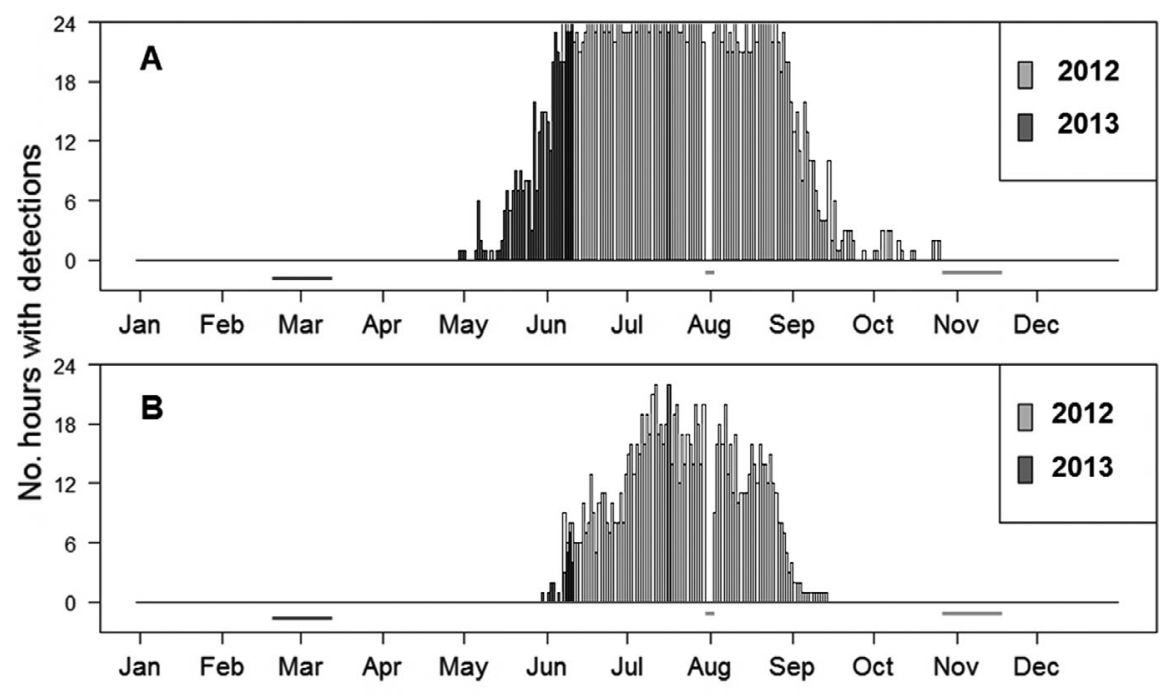

Fig. 3. Seasonal distribution of striped cusk eel Ophidion marginatum (A) calls and (B) cusk eel chorusing, shown as the number of hours per day in which detections occurred in each month. Data from both 2012 and 2013 are shown; instances where no recordings were made are indicated by horizontal bars underneath. (Light grey = 2012 ; darker grey $=2013$ ). The darkest areas of vertical bar graph indicate the overlap of 2012 and 2013 data. See Fig. S1 in the Supplement for chronological order 


\section{Monthly and lunar patterns}

Morning and evening chorus peak energy levels were compared across the months of June to September 2012 (Fig. 6A). Morning peak energy levels generally increased from June to July from an EFD median of 142 to $146 \mathrm{~dB}$ re $1{\mu \mathrm{Pa}^{2}}^{2}$ s. Levels were stable from July to August at a median of $146 \mathrm{~dB}$, and steeply dropped off in September to a median of $137 \mathrm{~dB}$. Ambient sound levels in the same band were approximately $120 \mathrm{~dB}$ re $1 \mu^{\mathrm{Pa}^{2} \mathrm{~s}}$ in the mid-fall (October) when cusk eels were no longer detected. The summer morning peak energy levels were significantly different across the months except between July and August $\left(\chi^{2}=42.41, \mathrm{p}<0.001\right)$. Variability in energy levels was substantially higher in June and September (with the 25-75 quartile ranges of 13 and $6 \mathrm{~dB}$, respectively), compared to July and August (both $4 \mathrm{~dB}$ ). There were similar differences in evening peak energy levels $\left(\chi^{2}=74.69, p<0.001\right)$ : like the morning levels, median evening values increased from June to July (146 to $152 \mathrm{~dB}$, respectively), but then decreased from August through September (medians of 151 to $139 \mathrm{~dB}$, respectively). Evening EFD 25-75 quartile ranges showed the same patterns as the morning values but were overall slightly lower $(4,1,2$, and $4 \mathrm{~dB}$ in June to September, respectively).

There was a significant effect of the lunar cycle on morning peak energy levels $\left(\chi^{2}=26.37, p<\right.$ 0.001), with new moon chorus levels higher (median of $147 \mathrm{~dB}$ ) than those during the full moon (median of $142 \mathrm{~dB} ; \mathrm{r}=0.65, \mathrm{p}<0.001)$, and during the last quarter phase of the moon $\left(145 \mathrm{~dB}_{i} \mathrm{r}=0.42, \mathrm{p}=0.01\right)$. Energy levels recorded during the first quarter moon $(146 \mathrm{~dB})$ were also significantly higher than those recorded during the full moon $(r=0.55, \mathrm{p}<0.001)$. There was no significant effect of the lunar cycle on evening peak energy levels $\left(\chi^{2}=4.18, p=0.24\right.$; Fig. 6$)$.

To examine a potential seasonal relationship between chorusing and time of day, the time of the peak chorus was compared to the time of sunrise and sunset in each month (Fig. 7). There was a clear relationship between the time that evening choruses occurred and time of sunset, with peak levels occurring just after sunset $\left(\mathrm{r}^{2}=0.71, F=235.04, \mathrm{p}<\right.$ 0.0001 ). Morning values showed greater variation both in timing of the peak and in energy levels across the summer months. These variations were greatest at the start and end of the summer period. However, peak levels still followed a weak but significant trend $\left(\mathrm{r}^{2}=0.09, F=9.55, \mathrm{p}<0.005\right)$ of occurring just before sunrise and tracking sunrise time across summer and early fall.
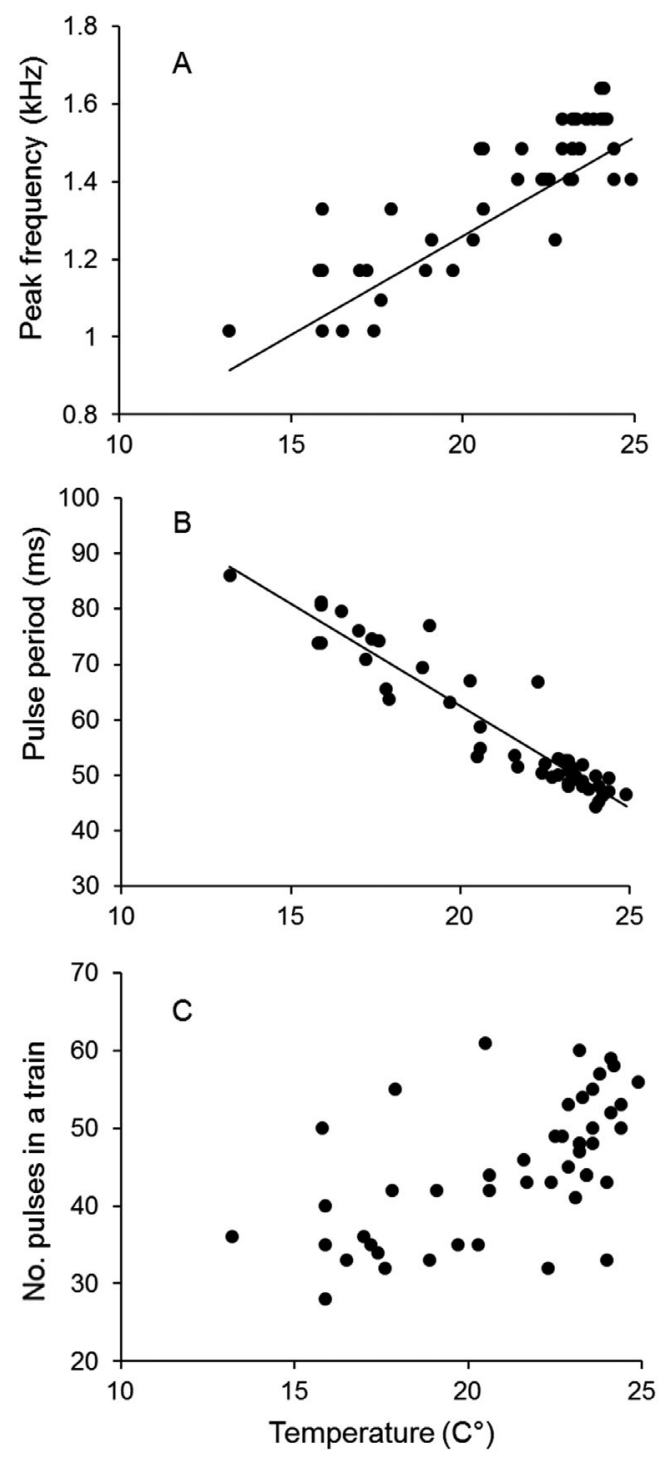

Fig. 4. Relationships between striped cusk eel Ophidion marginatum call parameters and water temperature. (A) Peak frequency increased linearly with increasing temperature $\left(\mathrm{r}^{2}=0.73, \mathrm{p}<0.0001\right.$; range $\left.13.3-25.1^{\circ} \mathrm{C}\right)$. (B) Pulse period decreased linearly with increasing temperature $\left(\mathrm{r}^{2}=\right.$ $0.89, \mathrm{p}<0.0001$ ). (C) There was no relationship between the number of pulses in a pulse train and temperature $\left(r^{2}=0.35, p>0.05\right)$

\section{DISCUSSION}

This work describes temporal patterns of cusk eel calls across approximately 1 yr in Nantucket Sound, MA, USA. Calls were detected only during the summer (June to September), and there were clear temporal patterns (e.g. diel, monthly, lunar) in calling behavior. These calling patterns were generally inversely associated with ambient light conditions (sunrise, sunset, and the new moon). For example, 

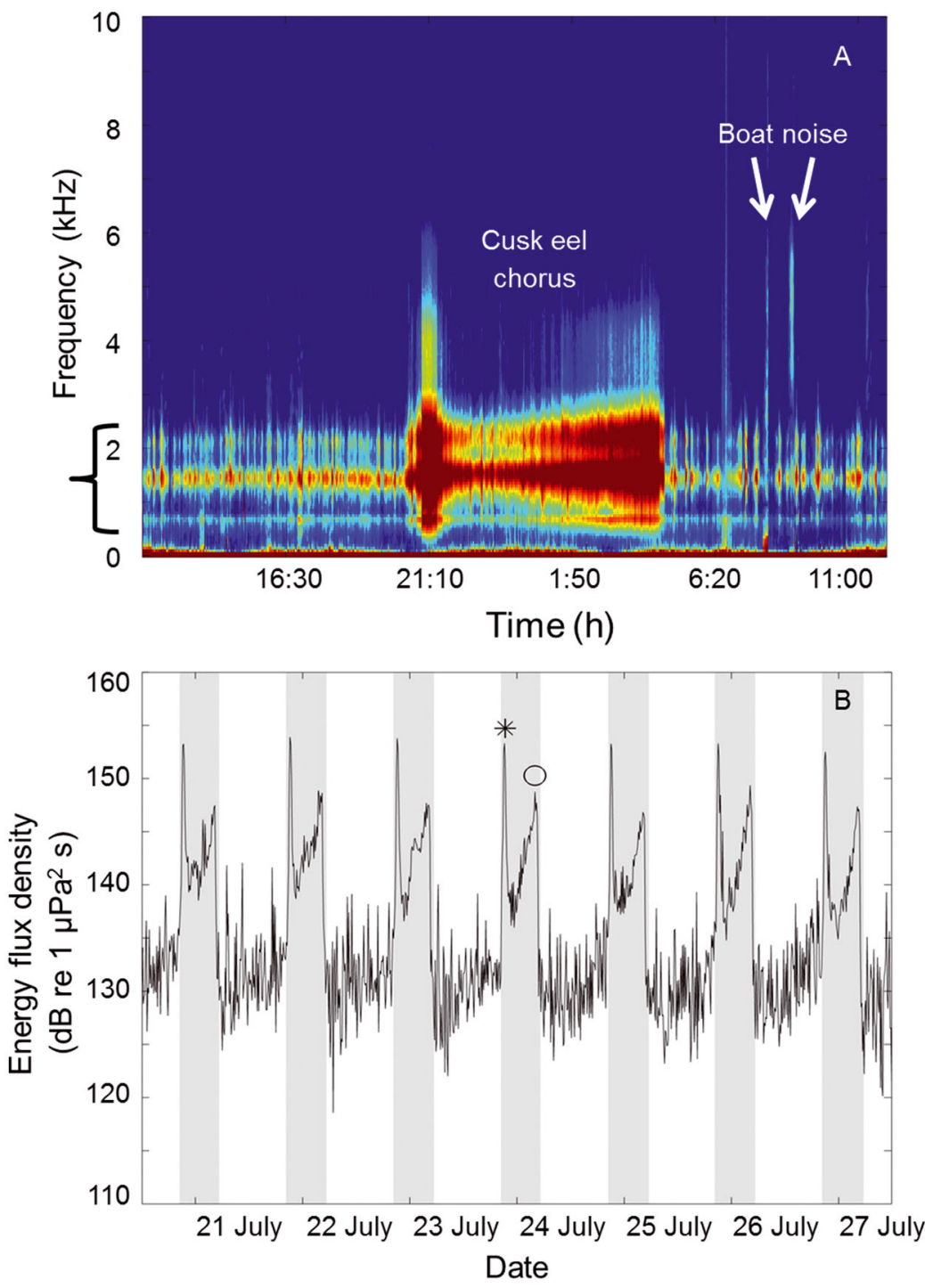

Fig. 5. (A) Long-term spectrogram from 23 July 2012. Energy sources come from striped cusk eels Ophidion marginatum and boats (arrows). Cusk eel sounds reflect near-constant chatter during the day (noted by the bracket on the left) and evening choruses (noted), reflecting differences in energy levels during the day and night periods. Time was averaged in $5 \mathrm{~s}$ bins and frequency was averaged in $50 \mathrm{~Hz}$ bins. (B) Energy flux density levels in the predominant cusk eel band (400 to $3000 \mathrm{~Hz}$ ) from noon 20 July to noon 27 July 2012. Areas shaded in gray denote the time between sunset and sunrise $(\sim 20: 00$ to $05: 30 \mathrm{~h})$. Chorusing peaks around the time of sunset (*, 20:00 $\mathrm{h})$ and sunrise $(\mathrm{O}, 05: 30 \mathrm{~h})$ are shown

cusk eel call energy peaked just after sunset and just before sunrise. Energy during the morning was also highest during new moons and lowest during full moons. Finally, call energy strongly followed seasonal changes in sunset times. As cusk eel calls function in reproduction, these patterns suggest an adaptation to attract mates and spawn during darkness or conditions where vision maybe be limited (such as turbid waters) (Lobel 1992, Mann \& Lobel 1998). Similar diel call periodicity has been noted in other systems (e.g. Aalbers 2008, Locascio \& Mann 2008). Darkness and turbidity could limit the efficiency of highly visual predators in the area such as striped bass Morone saxitilis and bluefish Pomatomus saltatrix, both of which are abundant during the summer months (Collette \& KleinMacPhee 2002). Thus, lower predation risk at night may be a factor driving night reproductive behavior. Further insights may be gained regarding the role of light levels in driving diel calling patterns by examining acoustic behavior of deeperdwelling fish found in habitats where light is limited (Mann \& Jarvis 2004, Kéver et al. 2015).

Temperature also influenced some call parameters, including peak frequency and the pulse period. Similar patterns have been noted elsewhere for other fish species (Fine 1978, Connaughton et al. 2002, Papes \& Ladich 2011, Kéver et al. 2015), reflecting the rather large role ectothermic physiology may play in acoustic communication.

While the number of cusk eels was not discernible from the recordings, the relatively high amplitude sound energy (>150 dB re $1 \mu^{2}{ }^{2}$ s) and overlap of calls during chorusing periods suggest that many fish were often simultaneously calling. These choruses substantially influenced the local soundscape, which had an ambient noise level of $120 \mathrm{~dB}$ or lower in the absence of cusk eel calling activity. Choruses occurred on a nightly basis across several summer months, resulting in cusk eels being the dominant energy producers in the 400 to $3000 \mathrm{~Hz}$ frequency band. Even though boats, other fish, wind, waves, rain, and tidal cycles also contributed energy in this range, those sounds tended to be more intermittent, or, in the case of tidal currents, flow noise was notable in full band analyses (and was clearly linked to tide schedules) but was not discernible when sound files were bandpass filtered. Although we do not know how spatially widespread the calling is, there seems to be a robust population of cusk eels in the area of the recorder. Future studies in this area would benefit from determining the source levels of individual cusk eel calls, as well as sound transmission characteristics of the environment, in order to assess the 

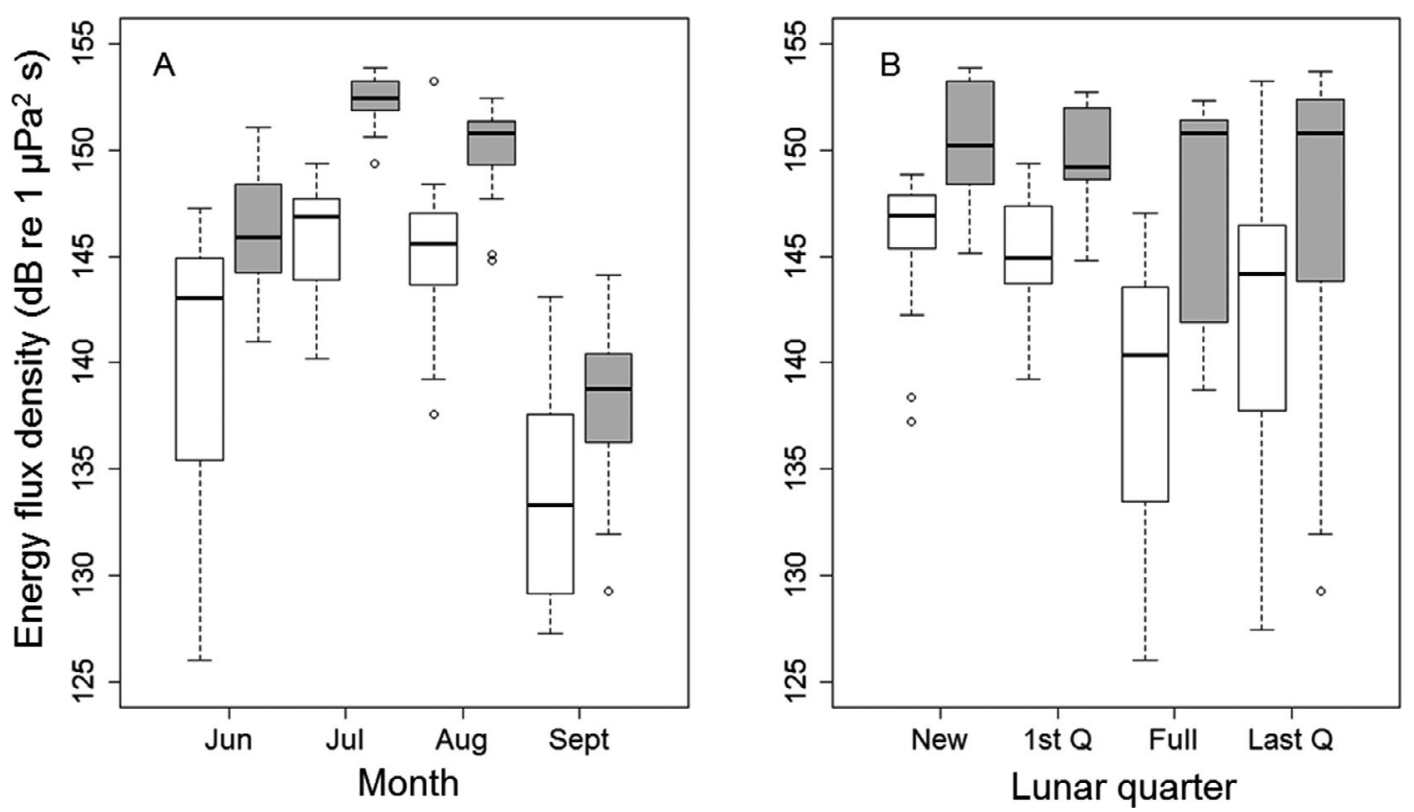

Fig. 6. Striped cusk eel Ophidion marginatum. (A) Morning (white) and evening (gray) peak energy levels from 8 June to 14 September 2012. Boxes show the median (middle bar), 1st and 3rd quartiles (upper and lower bounds of a box), outliers (open circles) and whiskers (9-91\%). Morning peak values were defined as the time with the most energy from 01:00 to 05:00 h (inclusive) in the 400 to $3000 \mathrm{~Hz}$ frequency range. Evening peak values were defined as the time with the most energy from 19:00 to $23: 00 \mathrm{~h}$ (inclusive) in the 400 to $3000 \mathrm{~Hz}$ frequency range. (B) Sound energy levels relative to phases of the moon (2012 data). The lunar calendar was obtained from http://eclipse.gsfc.nasa.gov/eclipse.html and lunar data were used at a daily resolution

potential for masking from anthropogenic noise sources.

The relative intensity and stereotypy of cusk eel calls and chorus patterns makes their detection relatively straightforward. Call levels or other parameters could serve as acoustic indicators for potential changes to this environment (i.e. changes in cusk eel populations). While these sounds likely relate to advertisement and/or mating, we do not currently understand how changes in cusk eel communication might translate into biologically meaningful effects on their reproductive success.

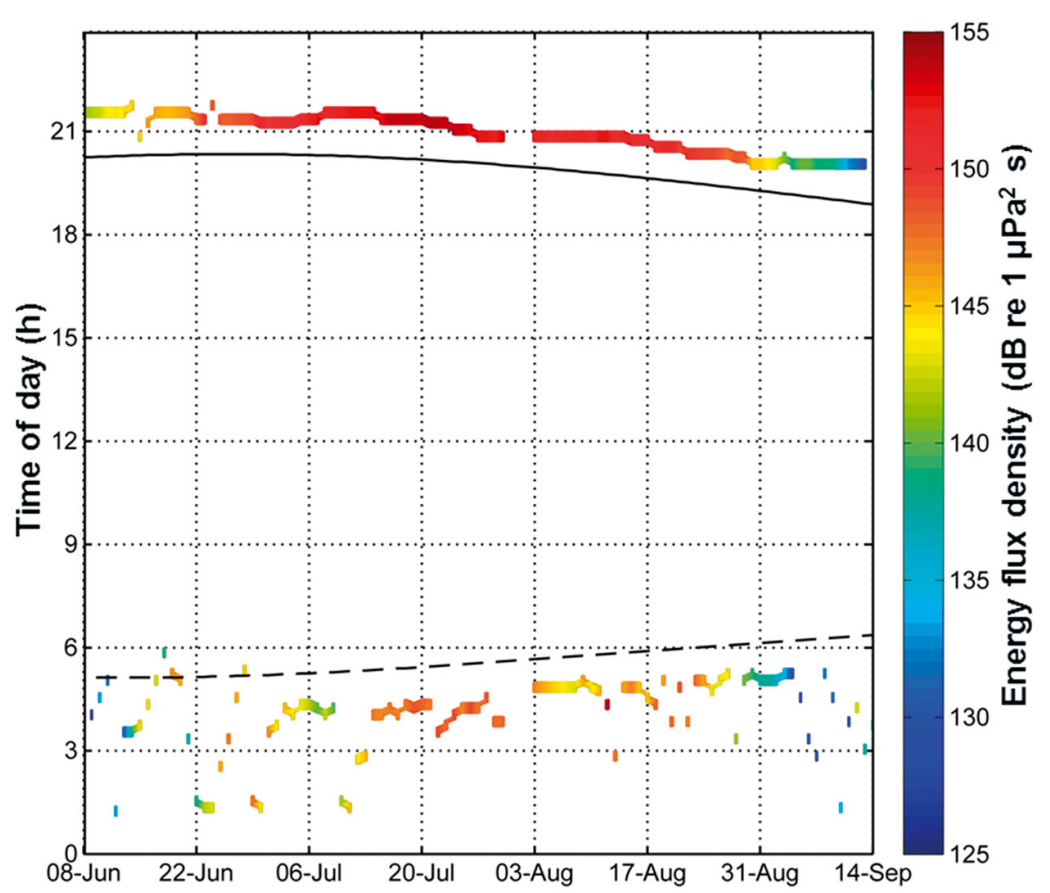

Fig. 7. Times of peak energy levels in the 400 to $3000 \mathrm{~Hz}$ band relative to sunrise and sunset times from 8 June to 14 September 2012. Sounds are represented by the colored points generally above the solid black line (sunset) or below the dashed black line (sunrise), these reflect the propensity of striped cusk eel Ophidion marginatum chorus energy to be just before sunrise or just after sunset, with the sunrise chorus notably more variable in time. Two bands of time were used to capture the 2 chorusing peaks, one from 01:00 to 05:00 $\mathrm{h}$ (inclusive), and the other from 19:00 to $23: 00 \mathrm{~h}$ (inclusive). Sunrise and sunset times were taken from http://aa.usno.navy. mil/data/docs/RS_OneYear.php. All times are local (Eastern Daylight Time). No data were obtained from 31 July to 2 August 2012 
Of particular interest in this area is the potential impact of noise from wind farm construction and operation (Madsen et al. 2006), given that it is one of the first proposed sites for an offshore wind farm in the USA. Wind farm-associated noise could include construction sounds (e.g. pile driving), wind-driven operation sounds, and the related vessel traffic supporting construction or servicing the turbines. Vessel noise likely contains frequencies that overlap those of cusk eel calls (our data as well as Madsen et al. 2006, Bailey et al. 2010, Kaplan \& Mooney 2015). Turbine operation sounds have the potential to be relatively constant, but they tend to be lower in frequency than cusk eel sounds (Madsen et al. 2006, Tougaard et al. 2009) and their low source levels suggest a limited range of masking influence. Pile driving sounds are fairly broadband and, given their high intensity (Bailey et al. 2010), may propagate long distances, although actual sound propagation is dependent on many factors and should be measured at each site (Madsen et al. 2006). However, their temporal periodicity may limit actual masking.

This study is only a first step toward quantifying the acoustic environment at Horseshoe Shoal and cusk eel temporal patterns. A more comprehensive assessment of the soundscape is necessary to assess potential impacts of wind farm construction and operation. This would include a broader assessment of biological, physical, and anthropogenic contributors to the local soundscape as well as increasing both the time frame of recorder deployments and the number of recorders to provide better spatial coverage within the area. But based on our data, a clear way to reduce masking of the cusk eel chorus would be to conduct construction operations during the day, when acoustic signaling seems to occur less often. Furthermore, it would be valuable to determine if masking noise actually impairs male reproductive advertisements, mate attractions or spawning coordination. It is also possible that wind farm noise may be a relatively small contribution to the overall soundscape energy during the summer period, given the high intensity of cusk eel calls and choruses in this area. Additionally, the clarity and stereotypy of the patterns and the overall energy of the cusk eel signals suggest that this taxon might serve as an acoustic indicator species for the local habitat if wind farm construction and operation proceed.

Acknowledgements. This research was funded by Woods Hole Sea Grant with additional support from the Island Foundation and the WHOI Coastal Ocean Institute. Analysis and field assistance was provided by A. Boucher, J. Car- duner, M. Wilsterman, D. Bogorff, A. Bocconcelli, A. Davies, T. Silva, and J. Samson. Conversations and project advice were provided by the Passive Acoustic Group of the Northeast Fisheries Science Center (NOAA).

\section{LITERATURE CITED}

Aalbers SA (2008) Seasonal, diel, and lunar spawning periodicities and associated sound production of white seabass (Atractoscion nobilis). Fish Bull 106:143-151

Au WWL (1993) The sonar of dolphins. Springer, New York, NY

Bailey H, Senior B, Simmons D, Rusin J, Picken G, Thompson PM (2010) Assessing underwater noise levels during pile-driving at an offshore windfarm and its potential effects on marine mammals. Mar Pollut Bull 60:888-897

Beaudry-Losique J, Boling T, Brown-Saracino J, Gilman P and others (2011) A national offshore wind strategy: creating an offshore wind energy industry in the United States. US Department of Energy, Washington, DC

Carstensen J, Henriksen OD, Teilmann J (2006) Impacts of offshore wind farm construction on harbour porpoises: acoustic monitoring of echolocation activity using porpoise detectors (T-PODs). Mar Ecol Prog Ser 321:295-308

Charif RA, Waack A, Strickman L (2010) Raven pro 1.4 user's manual. Cornell Laboratory of Ornithology, Ithaca, NY

Collette BB, Klein-MacPhee G (eds) (2002) Bigelow and Schroeder's fishes of the Gulf of Maine. Blackburn Press, Caldwell, NJ

Connaughton MA, Fine ML, Taylor MH (2002) Weakfish sonic muscle: influence of size, temperature and season. J Exp Biol 205:2183-2188

Courtenay WRJ (1971) Sexual dimorphism of the sound producing mechanism of the striped cusk-eel, Rissola marginata (Pisces: Ophidiidae). Copeia 259-268

Fine ML (1978) Seasonal and geographic variation of the mating call of the oyster toadfish Opsanus tau. Oecologia 36:45-57

Fish MP, Mowbray WH (1970) Sounds of western North Atlantic fishes. Johns Hopkins Press, Baltimore, MD

Hawkins AD, Amorim MCP (2000) Spawning sounds of the male haddock, Melanogrammus aeglefinus. Environ Biol Fishes 59:29-41

Hernandez KM, Risch D, Cholewiak DM, Dean MJ and others (2013) Acoustic monitoring of Atlantic cod (Gadus morhua) in Massachusetts Bay: implications for management and conservation. ICES J Mar Sci 70:628-635

Johnston CE, Vives SP (2003) Sound production in Codoma ornata (Girard) (Cyprinidae). Environ Biol Fishes 68: 81-85

Kaplan MB, Mooney TA (2015) Ambient noise and temporal patterns of boat activity in the US Virgin Islands National Park. Mar Pollut Bull 98:221-228

Kéver L, Boyle KS, Dragičević B, Dulčić J, Casadevall M, Parmentier E (2012) Sexual dimorphism of sonic apparatus and extreme intersexual variation of sounds in Ophidion rochei (Ophidiidae): first evidence of a tight relationship between morphology and sound characteristics in Ophidiidae. Front Zool 9:34

> Kéver L, Boyle KS, Parmentier E (2015) Effects of seawater temperature on sound characteristics in Ophidion rochei (Ophidiidae). J Fish Biol 87:502-509

> Lammers MO, Brainard RE, Au WWL, Mooney TA, Wong K (2008) An ecological acoustic recorder (ear) for long-term 
monitoring of biological and anthropogenic sounds on coral reefs and other marine habitats. J Acoust Soc Am 123:1720-1728

Lindeboom HJ, Kouwenhoven HJ, Bergman MJN, Bouma S and others (2011) Short-term ecological effects of an offshore wind farm in the Dutch coastal zone; a compilation. Environ Res Lett 6:035101

Lobel PS (1992) Sounds produced by spawning fish. Environ Biol Fishes 33:351-358

Lobel PS, Mann DA (1995) Courtship and mating sounds of Dascyllus albisella (Pomacentridae). Bull Mar Sci 57:705

- Locascio JV, Mann DA (2008) Diel periodicity of fish sound production in Charlotte Harbor, Florida. Trans Am Fish Soc 137:606-615

Luczkovich JJ, Sprague MW, Johnson SE, Pullinger RC (1999) Delimiting spawning areas of weakfish Cynoscion regalis (family Sciaenidae) in Pamlico Sound, North Carolina using passive hydroacoustic surveys. Bioacoustics 10:143-160

> Madsen P, Wahlberg M, Tougaard J, Lucke K, Tyack P (2006) Wind turbine underwater noise and marine mammals: implications of current knowledge and data needs. Mar Ecol Prog Ser 309:279-295

Mann DA, Grothues TM (2009) Short-term upwelling events modulate fish sound production at a mid-Atlantic Ocean observatory. Mar Ecol Prog Ser 375:65-71

Mann DA, Jarvis SM (2004) Potential sound production by a deep-sea fish. J Acoust Soc Am 115:2331-2333

Mann DA, Lobel PS (1995) Passive acoustic detection of fish sound production associated with courtship and spawning. Bull Mar Sci 57:705-706

Mann DA, Lobel PS (1998) Acoustic behavior of the damselfish Dascyllus albisella: behavioral and geographic variation. Environ Biol Fish 51:421-428

Mann DA, Bowers-Altman J, Rountree RA (1997) Sounds produced by the striped cusk-eel Ophidion marginatum (Ophidiidae) during courtship and spawning. Copeia 1997:610-612

Montie EW, Vega S, Powell M (2015) Seasonal and spatial patterns of fish sound production in the May River, South Carolina. Trans Am Fish Soc 144:705-716

Myrberg AA (1986) Sound producing by males of a coral reef fish (Pomacentrus partitus): its significance to females. Anim Behav 34:913-923

Editorial responsibility: Brent Stewart,

San Diego, California, USA
Nielsen JG, Cohen DM, Markle DF, Robins CR (1999) FAO species catalogue, Vol 18. Ophidiiform fishes of the world (Order Ophidiiformes). An annotated and illustrated catalogue of pearlfishes, cusk-eels, brotulas and other ophidiiform fishes known to date. FAO Fish Synop 125, FAO, Rome

> Papes S, Ladich F (2011) Effects of temperature on sound production and auditory abilities in the striped raphael catfish Platydoras armatulus (family Doradidae). PLoS ONE 6:e26479

Parmentier E, Bouillac G, Dragi evi B, Dul i J, Fine ML (2010) Call properties and morphology of the soundproducing organ in Ophidion rochei (Ophididae). J Exp Biol 213:3230-3236

> Perkins PJ (2001) Drumming and chattering sounds recorded underwater in Rhode Island. Northeast Nat 8: 359-370

R Development Core Team (2010) R: a language and environment for statistical computing, R Foundation for Statistical Computing, Vienna

Radford C, Jeffs A, Tindle C, Montgomery JC (2008a) Resonating sea urchin skeletons create coastal choruses. Mar Ecol Prog Ser 362:37-43

Radford CA, Jeffs A, Tindle C, Montgomery J (2008b) Temporal patterns in ambient noise of biological origin from a shallow water temperate reef. Oecologia 156:921-929

Rountree RA, Perkins PJ, Kenney RD, Hinga KR (2002) Sounds of western North Atlantic fishes: data rescue. Bioacoustics 12:242-244

Sprague M, Luczkovich J (2001) Do striped cusk-eels Ophidion marginatum (Ophidiidae) produce the 'chatter' sound attributed to weakfish Cynoscion regalis (Sciaenidae)? Copeia 2001:854-859

Teilmann J, Carstensen J (2012) Negative long term effects on harbour porpoises from a large scale offshore wind farm in the Baltic-evidence of slow recovery. Environ Res Lett 7:045101

> Tougaard J, Henriksen OD, Miller LA (2009) Underwater noise from three types of offshore wind turbines: estimation of impact zones for harbor porpoises and harbor seals. J Acoust Soc Am 125:3766-3773

Versluis M, Schmitz B, von der Heydt A, Lohse D (2000) How snapping shrimp snap: through cavitating bubbles. Science 289:2114-2117

Submitted: August 25, 2015; Accepted: January 19, 2016 Proofs received from author(s): February 15, 2016 